\title{
Role of Human Chorionic Gonadotrophin Compared to 17-Alpha-Hydroxyprogesterone in the Management of Threatened Abortion: Experience in a Military Hospital in Dhaka, Bangladesh
}

\author{
Khanum $\mathrm{S}^{\mathrm{a}^{*}}$, Ahmed JU $\mathrm{b}^{*}$
}

\begin{abstract}
Background: Threatened abortion is the most common complication in the first half of gestation. Spontaneous abortion occurs in less than $30 \%$ of the women who experience threatened abortion. In order to prevent pregnancy loss several supportive therapies including hormonal therapy like human chorionic gonadotropin ( $h C G)$ or 17-alpha-hydroxyprogesterone (progesterone) have been advocated. The exogenous administration of $h C G$ is aimed at stimulating and therefore optimizing progesterone production. Aim of this study was to compare the efficacy of supportive therapy with hCG and progesterone in women with threatened abortion.

Methods: This prospective study was carried out in the department of obstetrics and gynecology of the Combined Military hospital (CMH), Savar, Dhaka, Bangladesh from July 2016 to June 2017. One hundred pregnant patients admitted with the history of per vaginal bleeding before 20 weeks of gestation without having any other co-morbidity were included in this study. Patients were randomized to two treatment groups. The participants in group $A(52,52 \%)$ received injection $h C G$ weekly while those in group B $(48,48 \%)$ received injection progesterone from recruitment up until 20 weeks of gestation. Further USG were performed one week and four weeks after recruitment to the study and again at 20 weeks and subsequently when indicated. The final outcome of pregnancy were recorded and analyzed.
\end{abstract}

Results: Among 100 patients majority belonged to the 26-30 year age group. Mean age of the patients was $27.2 \pm 10.5$ years. There was not much significant difference between the groups in terms of parity. More than $75 \%$ of patients in both the groups presented before 16 weeks of gestation with threatened abortion. In both the groups more than $75 \%$ of the patients had previous history of pregnancy loss. In terms of pregnancy outcome more patients in $h C G$ group had live pregnancy than progesterone group (88.5\% vs 66.7\%) (p=0.012). Out of 46 live birth in hCG group, 4 (7.7\%) were preterm labor between 31-35 weeks of pregnancy and one baby died in neonatal ICU, one died at 31 weeks of gestation which was delivered by vaginally. On the other hand out of 32 live birth in progesterone group, there was $3(6.3 \%)$ preterm labor. Growth retardation was less in hCG group compared to progesterone group $(9.6 \% \mathrm{vs} 14.6 \%)$. However cesarean section rate was high in both the groups.

Conclusion: Treatment with injection $h C G$ has better pregnancy outcome than that of injection17-alphahydroxyprogesterone in early pregnancy with threatened abortion of unexplained cause.

Key words: Threatened abortion, human chorionic gonadotrophin, 17-á-hydroxyprogesterone.

(BIRDEM Med J 2019; 9(1): 7-10)

Author Information

a. Lieutenant Colonel (Dr.) Shakila Khanum, FCPS (Obs \& Gyn), MCPS (Obs \& Gyn), Classified Specialist in Obstetrics \& Gynecology, Combined Military Hospital, Savar, Dhaka, Bangladesh

b. Dr. Jamal Uddin Ahmed, FCPS (Medicine), Associate Professor of Medicine, BIRDEM General Hospital \& Ibrahim Medical College, Dhaka, Bangladesh

** Since both the authors have equal contribution to the article, they both will be considered as first author of the article.*

Address of correspondence: Major (Dr.) Shakila Khanum, Classified Specialist, Department of Obstetrics \& Gynecology, Combined Military Hospital, Savar, Dhaka, Bangladesh. E-mail: shakilashathi85@gmail.com

Received: September 16, 2018

Accepted: October 31, 2018

\section{Introduction}

Threatened abortion is a condition that occurs before 20 weeks of pregnancy where there is bleeding in choriodecidual space, but this is not sufficient to kill the embryo ${ }^{1}$. It is the most common complication in the first half of gestation ${ }^{2}$. Most of these pregnancies continue to term with or without treatment. Spontaneous abortion occurs in less than $15-25 \%$ of the women who experience threatened abortion and they are 2.6 times more likely to miscarry as compared to pregnant women with no bleeding ${ }^{3}$. 
Threatened abortion occurs in about $20 \%$ of early pregnancy and $50-60 \%$ are due to chromosomal abnormalities ${ }^{4}$. Apart from the fetal factors, several maternal and probably some paternal factors contribute to the causes of spontaneous abortion ${ }^{4,5}$. No cause can be identified in approximately $40-50 \%$ women with threatened abortion ${ }^{5}$.

In case of unexplained pregnancy loss several supportive therapies have been advocated. These include bed rest, avoid coitus and hormonal therapy (human chorionic gonadotropin or 17-alpha-hydroxyprogesterone) ${ }^{6}$. Endogenous human chorionic gonadotrophins (hCG) are known to play a vital physiological part in the establishment of early pregnancy. The exogenous administration of $\mathrm{hCG}$ is aimed at stimulating and therefore optimizing progesterone production firstly in the corpus luteum and later in the fetoplacental unit. hCG therapy therefore appears to be a logical approach when an endocrine abnormality is suspected.

There is some evidence for the benefit of hCG in women suffering from recurrent miscarriage. One study comprising of women with history of both recurrent miscarriage and oligomenorrhoeic cycles found that the risk of miscarriage decreases by treatment with hCG. On the other hand a Cochrane review on use of hCG treatment for the prevention of recurrent miscarriage concluded that there was insufficient evidence to support its use in routine clinical practice ${ }^{7}$.

Considering these conflicting evidences this study was aimed to compare the efficacy of supportive therapy with hCG and progesterone in women with threatened abortion.

\section{Methods}

This prospective study was carried out in the department of obstetrics and gynecology of the Combined Military hospital (CMH), Savar, Dhaka, Bangladesh from July 2016 to June 2017. Pregnant patients admitted with the history of per vaginal bleeding before 20 weeks with a viable fetus without having any other co-morbidity were included in this study. Diagnosis of threatened abortion was confirmed from history, clinical examination and abdominal ultrasound (USG) finding of alive fetus. Patients with history of genital tract abnormalities, those having any underlying medical conditions like hypertension, hypothyroidism and diabetes mellitus were excluded from the study. A total 158 patients presented with threatened abortion during this time. Among them 100 patients fulfilled the inclusion criteria. Following proper counselling and after receiving informed written consent, patients were divided to two study groups (Table I). The participants in group A $(52,52 \%)$ received injection hCG weekly from recruitment up until 20 weeks of gestation while those in group B $(48,48 \%)$ received injection 17-alpha-hydroxy progesterone in same dose and duration. There were no reports of adverse effects from either of the treatment group. Further USG were performed one week and four weeks after recruitment to the study and again at 20 weeks. All participants had otherwise routine hospital or community antenatal care; however, further scans were performed for recurrent bleeding or any other indication. All women received supportive care including folic acid supplementation, recommended bed rest and were followed routinely in outpatient department (OPD). Women were only admitted in hospital during the treatment period, if they had any vaginal bleeding or a medical condition that required hospital admission. The groups at presentation were comparable in age, parity, gestational age at the start of therapy. Pregnancy outcome was observed by mean of early pregnancy loss (missed abortion, incomplete abortion), preterm labor, intrauterine growth retardation (IUGR), intrauterine fetal death (IUD) and live pregnancy up to delivery. The final outcome of pregnancy were recorded and analyzed. Data were collected in a structured questionnaire. Collected data was analyzed by SPSS version 22.0.

\section{Results}

A total of 158 women with threatened miscarriage were recruited to the study, of whom 100 (75\%) complied fully with the study protocol. Among 100 patients majority belonged to the 26-30 year age group (Table II). Mean age of the patients was $27.2 \pm 10.5$ years. There was not much significant difference between the groups in terms of parity (Table III). More than $75 \%$ of patients in both the groups presented before 16 weeks of gestation with threatened abortion (Table IV). In both the groups more than $75 \%$ of the patients had previous history of pregnancy loss (Table V). In terms of pregnancy outcome more patients in group A had live pregnancy than group $\mathrm{B}$ (Table VI) $(\mathrm{p}=0.012)$. Out of 46 live birth in the group A, 4 (7.7\%) were preterm labor between 31-35 weeks of pregnancy and one baby died in neonatal ICU, one died at 31 weeks of gestation which was delivered by vaginally. On the other hand out of 32 live birth in group B, there was $3(6.3 \%)$ preterm labor. Growth retardation was more in group B (Table VI). However cesarean section rate was high in both the groups (Table VII). No live born baby was reported to have any congenital malformation and all are developing normally to date. In cases where the pregnancy was successful, few complications were noted. 


\begin{tabular}{l}
$\begin{array}{l}\text { Table I Distribution of patients according to } \\
\text { treatment group }(\mathrm{n}=100)\end{array}$ \\
\begin{tabular}{|llc} 
Group & Treatment received & $\begin{array}{c}\text { No. of patients } \\
\text { (percentage) }\end{array}$ \\
\hline A & $\begin{array}{l}\text { Injection Human chorionic } \\
\text { Gonadotropin (hCG) }\end{array}$ & $52(52 \%)$ \\
Injection 17-alpha- \\
Hydroxyprogesterone
\end{tabular} \\
\hline
\end{tabular}

Table II Age distribution of patients $(\mathrm{n}=100)$

\begin{tabular}{lcc}
\hline Age (years) & $\begin{array}{c}\text { Group A }(\mathrm{n}=52) \\
\text { number }(\%)\end{array}$ & $\begin{array}{c}\text { Group B }(\mathrm{n}=48) \\
\text { number }(\%)\end{array}$ \\
\hline$<19$ & $02(3.8 \%)$ & $04(8.3 \%)$ \\
$20-25$ & $14(26.9 \%)$ & $16(33.3 \%)$ \\
$26-30$ & $22(42.3 \%)$ & $18(37.5 \%)$ \\
$31-35$ & $12(23.1 \%)$ & $08(16.7 \%)$ \\
$>36$ & $02(3.8 \%)$ & O2 $(4.2 \%)$ \\
\hline
\end{tabular}

Table III Distribution of patients according to parity
$(\mathrm{n}=100)$

Table IV Distribution of patients according to weeks of pregnancy at presentation $(\mathrm{n}=100)$

\begin{tabular}{lcc}
\hline $\begin{array}{l}\text { Weeks of } \\
\text { pregnancy }\end{array}$ & $\begin{array}{c}\text { Group A }(\mathrm{n}=52) \\
\text { number }(\%)\end{array}$ & $\begin{array}{c}\text { Group B }(\mathrm{n}=48) \\
\text { number }(\%)\end{array}$ \\
\hline $6-9$ & $23(44.2 \%)$ & $16(33.3 \%)$ \\
$10-15$ & $18(34.6 \%)$ & $20(41.7 \%)$ \\
$16-20$ & $11(21.2 \%)$ & $12(25.0 \%)$ \\
\hline
\end{tabular}

Table $\mathbf{V}$ Distribution of patients according to previous pregnancy loss

\begin{tabular}{lcc}
\hline $\begin{array}{l}\text { Number of previous } \\
\text { pregnancy loss }\end{array}$ & $\begin{array}{c}\text { nroup A }(\mathrm{n}=29) \\
\text { number }(\%)\end{array}$ & $\begin{array}{c}\text { nroup B }(\mathrm{n}=22) \\
\text { number }(\%)\end{array}$ \\
0 & $8(27.6 \%)$ & $5(22.7 \%)$ \\
1 & $10(34.5 \%)$ & $7(31.8 \%)$ \\
2 & $8(27.6 \%)$ & $9(40.9 \%)$ \\
$>2$ & $3(10.3 \%)$ & $1(4.5 \%)$ \\
\hline
\end{tabular}

Table VI Distribution of patients according to pregnancy outcome $(\mathrm{n}=100)$

\begin{tabular}{lccc}
\hline Pregnancy Outcome & $\begin{array}{c}\text { Group A } \\
(\mathrm{n}=52) \\
\text { number (\%) }\end{array}$ & $\begin{array}{c}\text { Group B } \\
(\mathrm{n}=48)\end{array}$ & $\begin{array}{c}\mathrm{p} \\
\text { namber (\%) }\end{array}$ \\
\hline Live pregnancy & $46(88.5 \%)$ & $32(66.7 \%)$ & 0.012 \\
Early pregnancy loss $04(7.7 \%)$ & $08(16.7 \%)$ & \\
IUD & $01(1.9 \%)$ & 00 & \\
Preterm labor & $04(7.7 \%)$ & $03(6.3 \%)$ & IUGR \\
O5 (9.6\%) & $07(14.6 \%)$ & & \\
\hline
\end{tabular}

[Multiple response in one patient is present]

Table VII Distribution of patients according to mode of delivery in live pregnancy

\begin{tabular}{lcc}
\hline Mode of Delivery & $\begin{array}{c}\text { Group A } \\
(\mathrm{n}=46) \\
\text { number }(\%)\end{array}$ & $\begin{array}{c}\text { Group B } \\
(\mathrm{n}=32) \\
\text { number }(\%)\end{array}$ \\
\hline Normal vaginal delivery & $18(39.1 \%)$ & $14(43.8 \%)$ \\
Assisted vaginal delivery & $2(4.3 \%)$ & $1(3.1 \%)$ \\
Cesarean section & $26(56.5 \%)$ & $17(53.1 \%)$ \\
\hline
\end{tabular}

\section{Discussion}

In this study the mean age of the patients was around 27 years which is almost similar to other studies ${ }^{8}$. Majority of the patients in both groups belonged to 26-30 year age group which is higher than another study, probably due to high age of marriage in military personnel ${ }^{9}$.

Similar to another study there was no significant difference among groups in terms of parity and majority of the patients in hCG group presented before 9 weeks of pregnancy ${ }^{8}$.

In this study most of the pregnancy continued till term but the live pregnancy rate was more in hCG group than progesterone group ( $88.5 \%$ vs $66.7 \%$ ). This finding is somehow different from another study where the live pregnancy rate was almost similar $(86.4 \%$ vs $79.1 \%)$ in both group 9 .

Unlike a recent study, there was no significant difference in occurrence of intrauterine growth retardation, preterm delivery in this study ${ }^{10}$. This dissimilarity could be due to the difference in the populations studied.

In this study the miscarriage rate was $17 \%$ in the progesterone group and $8 \%$ in the hCG group, which 
contrasts with $3.4 \%$ miscarriage rate as found in one study $^{11}$, but is broadly in agreement with the $10 \%$ incidence of miscarriage at six weeks of gestation found in another study ${ }^{12}$.It seems likely that the incidence of fetal loss between 6 and 10 weeks of gestation in threatened miscarriage patients will be dependent upon other factors such as maternal age or amount of vaginal bleeding and at least one repeat USG is necessary for effective diagnostic and prognostic value in such cases.

Limitations of this study include the small sample size and a single center study. Similar studies with large number of patients are warranted to establish universal adaptation guideline in all women to prevent early pregnancy loss.

\section{Conclusion}

From the results of this study it appears that human chorionic gonadotrophin is better than 17-alphahydroxyprogesterone, in treating women with threatened abortion of unknown cause or where a hormonal imbalance is suspected. Though progesterone is cost effective and convenient to patient but outcome of pregnancy better in hCG. So that hCG can be a better treatment option in women early pregnancy with threatened abortion of unexplained cause.

Conflict of interest: Nothing to declare.

\section{References}

1. Dongol A, Mool S, Tiwari P. Outcome of pregnancy complicated by threatened abortion. Kathmandu Univ Med J 2011; 9:41-44.

2. Sotiriadis A, Papatheodorou S, Makrydimas G. Threatened miscarriage: evaluation and management. BMJ 2004; 329: $152-155$.
3. Basama FM, Crosfill F. The outcome of pregnancies in 182 women with threatened miscarriage. Arch Gynecol Obstet 2004; 270:86-90.

4. Tank PD. Early pregnancy complications. In: Bhide A, Arulkumaran S, Damania KR, Daftary SN eds. Aria's Practical guide to high risk pregnancy $\&$ delivery; $4^{\text {th }}$ ed. New Delhi: Elsevier 2015; p. 104-14.

5. Parihard M, Bharath M. Recurrent Spontaneous Abortion: Current choices in treatment. Desai P, Malhotra N, Shah D eds. Principles \& practice of obstetrics \& gynecology for postgraduates, 3rd ed. New Delhi : Jaypee brothers 2008; p. 164-72.

6. Aleman A, Althabe F, Belizan J. Bergel E. Bed rest during pregnancy for preventing miscarriage. Cochrane Database Syst Rev 2005; 2: CD003576.

7. Devaseelan P, Fogarty PP, Regan L. Human chorionic gonadotrophin for threatened miscarriage. Cochrane Database Syst Rev 2010; (5): CD007422. doi: 10.1002/ 14651858.CD007422.pub2

8. Qureshi NS, Edi-Osagie EC, Ogbo V, Roy S, Hopkins RE. First trimester threatened miscarriage treatment with hunman chorionic gonadotrophins: a randomized controlled trial, BJOG 2005; 112: 1536- 41.

9. Saha E, Begum F, Jesmin FM. Role of human chorionic gonadotrophin to prevent repeated early pregnancy loss. Bang Med J Khulna 2015; 48: 7-10.

10. Weiss JL, Malone FD, Vidaver J. Threatened miscarriage: a risk factor for poor pregnancy outcome, a population based screening study. Am J Obstet Gynecol 2004; 190:745-50.

11. Tannirandorn Y, Sangsawang S, Manotaya S, Uerpairojkit B, Samritpradit P, Charoenvidhya D. Fetal loss in threatened abortion after embryonic or fetal heart activity. Int J Gynecol Obstet 2003; 81:263-66.।

11. Makrydimas G, Sebire NJ, Lolis D, Vlassis N, Nicolaides KH. Fetal loss following ultrasound diagnosis of a live fetus at 6 10 weeks of gestation. Ultrasound Obstet Gynecol 2003; 22:368-72. 